\title{
Factors influencing the size distribution of aerosols from jet nebulisers
}

\author{
MICHELLE M CLAY, DEMETRI PAVIA, STEPHEN P NEWMAN, STEWART W CLARKE \\ From the Department of Thoracic Medicine, Royal Free Hospital and School of Medicine, London
}

ABSTRACT The size distribution of saline and bronchodilator (terbutaline) aerosol droplets generated from four widely used jet nebulisers (Acorn, Upmist, Turret, and Inspiron Mini-neb) has been measured with a Malvern 2200 Laser Particle Sizer. The mass median diameter of aerosol droplets generated by each nebuliser was strongly influenced by the driving flow rate of compressed air. By increasing the flow rate from 4 to $81 \mathrm{~min}^{-1}$ mass median diameters were halved ( $\mathrm{p}<$ 0.01 ) and there was an increase in the mass of aerosol within the optimum respirable range $(<5 \mu \mathrm{m})$. To achieve this range the following individual flow rates were required: Turret $41 \mathrm{~min}^{-1}$, Acorn and Upmist $61 \mathrm{~min}^{-1}$, and Inspiron Mini-neb $81 \mathrm{~min}^{-1}$. A significant inverse relation ( $p<0.001$ ) was found between mass median diameter and the geometric standard deviation, indicating that the aerosols were smaller but more heterodisperse at high flow rates. Changes in drug concentration had little effect on aerosol size. In $72 \%$ of the nebulisations followed to dryness there was no significant change in mass median diameter during the course of nebulisation and in the remainder it was less than $1.3 \mu \mathrm{m}$.

Inhaled aerosols have considerable advantages in the treatment of many lung diseases, including asthma, bronchitis, and cystic fibrosis. ${ }^{1-3}$ The dose required is small in comparison with that taken systemically and the side effects are therefore negligible; the onset of action is more rapid, and the drug itself is more selective. ${ }^{4}$

The upper airways (nose, mouth, larynx, and pharynx) and the branching anatomy of the tracheobronchial tree act as a series of filters for inhaled particles. Thus particles larger than $10 \mu \mathrm{m}$ will not penetrate the tracheobronchial tree. On the other hand, particles of $0.5 \mu \mathrm{m}$ will penetrate the lungs deeply but have a high tendency to be exhaled without deposition. ${ }^{5}$ It has been shown that the optimum size for a $\beta$-adrenergic bronchodilator aerosol such as terbutaline is less than $5 \mu \mathrm{m}$ in diameter. ${ }^{6}$

Jet nebulisers have recently become popular for the delivery of therapeutic aerosols in hospitals and to a lesser extent in the patient's home. Details of the aerosols generated by such devices, however, are often lacking. If the size distribution is inappropri-

Address for reprint requests: MM Clay, Department of Thoracic Medicine, Royal Free Hospital, London NW3 2QG.

Accepted 16 May 1983 ate, little or no aerosol may be deposited in the lung and consequently there may be an inadequate effect.

The aim of this study was to measure the size distribution of aerosols generated by popular makes of jet nebuliser under typical operating conditions.

\section{Methods}

Four common makes of disposable jet nebulisers were selected for study. These were the Acorn, Upmist, and Turret (all Medic-aid Ltd) and the Inspiron Mini-neb (Bard International Ltd). Five nebulisers of each make were assessed. In each case all five were drawn from the same production batch.

Aerosol is generated from jet nebulisers by forcing compressed air (or oxygen) through a narrow orifice. The negative pressure created by the expanding jet from the orifice causes the respirator solution to be drawn up a feedtube and then broken up into droplets by the jet. Baffle structures within the nebuliser filter the aerosol and large droplets (which may constitute as much as $99 \%$ of the particles formed) are impacted on them and run back into the reservoir to be recirculated. ${ }^{7}$

In all experiments the nebulisers were driven by compressed air from a cylinder whose flow rate was controlled by a reducing valve and inline rotameter. Three air flow rates were employed to drive the 
nebulisers: 4,6 , and $81 \mathrm{~min}^{-1}$.

The nebulisers were charged with $4 \mathrm{ml}$ of the three test solutions-physiological saline and two solutions of the $\beta$-agonist terbutaline sulphate (Bricanyl Respirator Solution, Astra Pharmaceuticals), in concentrations of 2.5 and $5.0 \mathrm{mg} \mathrm{ml}^{-1}$ diluted with physiological saline. We wished to ascertain the effect of varying the concentration of respirator solution on the size distribution of the aerosols generated.

A Malvern 2200 Laser Particle Sizer (Malvern Instruments) was used to measure the size distributions of aerosols during a standardised nebulisation procedure. The $4 \mathrm{ml}$ of respirator solution was placed inside the nebuliser, which was then clamped into a vertical position so that the aerosol released would pass through the helium neon laser beam of the particle sizer $1 \mathrm{~cm}$ from the mouthpiece. In all experiments the mouthpiece was attached to a $\mathrm{T}$-piece that was fitted directly on to the nebuliser. The measurements were made under ambient conditions of temperature and humidity, which were monitored on each experimental day with a whirling hygrometer (Casella Instruments). Aerosol was prevented from refluxing into the beam by venting it away via a funnel attached to a fluid trap and suction pump.

Three measurements were made during nebulisation, at the start (time $0^{\prime}$ ) and at 3 and 6 minutes. A sampling time of 12 seconds ensured that a representative sample of aerosol was measured. Aerosol passing through the beam caused diffraction of the monochromatic light at angles inversely proportional to the diameters of the droplets. The diffraction pattern created by all the droplets sampled was stored and fed into a digital computer, which then reconstructed the size distribution of the aerosol. The size distribution was presented as the percentage of the cumulative mass or volume of the aerosol contained in droplets smaller than each of 16 size bands. This enabled the aerosol size distribution to be described by its mass median diameter (MMD: the droplet diameter above which $50 \%$ of the mass of respirator solution was contained) and $\overparen{D}$ the geometric standard deviation (GSD: the ratio between the $84.13 \%$ and $50 \%$ cumulative mass diameters). ${ }^{8}$

Non-parametric statistics were used to examine changes in mass median diameter. These were the Friedman and Kruskal-Wallis analyses of variance and the Wilcoxon rank sum test for paired and unpaired data. ${ }^{9} \mathrm{~A} p$ value of 0.05 was taken to indicate statistical significance.

\section{Results}

The mass median diameters of the aerosols generated by the four makes of nebuliser at the start of nebulisation (time $0^{\prime}$ ) and at 3 and 6 minutes for the various flow rates and drug concentrations are shown in the table. Each value represents the mean for the five nebulisers of each make assessed.

A total of 36 experimental conditions were investigated ( 3 flow rates $\times 3$ respirator solutions $\times 4$ makes of nebuliser). In 26 of these ( $72 \%$ ) there was no significant change in mass median diameter during the nebulisation process; in $10(28 \%)$ there was a significant change $(p<0.05)$, although the magnitude of this change was less than $1.3 \mu \mathrm{m}$.

The different respirator solutions produced significant changes in mass median diameter on only two occasions: Acorn nebuliser at $61 \mathrm{~min}^{-1}$ and Upmist nebuliser at $81 \mathrm{~min}^{-1}(\mathrm{p}<0.05)$, when the change in mass median diameter was less than $1 \mu \mathrm{m}$.

The flow rate of compressed air driving the nebulisers exerted an appreciable effect on the

Mass median diameters ( $\mu \mathrm{m}$ ) of the aerosols generated by the four makes of nebuliser (means of values obtained with five nebulisers of each make) under various experimental conditions

\begin{tabular}{|c|c|c|c|c|c|c|c|c|c|c|}
\hline & \multirow{3}{*}{$\begin{array}{l}\dot{V} \\
\left(l \min ^{-1}\right)\end{array}$} & \multicolumn{3}{|c|}{ Physiological saline } & \multicolumn{6}{|c|}{ Terbutaline in saline } \\
\hline & & \multirow[t]{2}{*}{$T=0^{\prime}$} & \multirow[t]{2}{*}{$T=3^{\prime}$} & \multirow[t]{2}{*}{$T=6^{\prime}$} & \multicolumn{3}{|c|}{$2.5 \mathrm{mg} \mathrm{ml}^{-1}$} & \multicolumn{3}{|c|}{$5.0 \mathrm{mg} \mathrm{ml}^{-1}$} \\
\hline & & & & & $T=0^{\prime}$ & $T=3^{\prime}$ & $T=6^{\prime}$ & $T=0^{\prime}$ & $T=3^{\prime}$ & $T=6^{\prime}$ \\
\hline Upmist & $\begin{array}{l}4 \\
6 \\
8 \\
4 \\
6 \\
8\end{array}$ & $\begin{array}{l}6 \cdot 2 \\
4 \cdot 2 \\
2 \cdot 3 \\
6 \cdot 6 \\
4 \cdot 5 \\
3 \cdot 2\end{array}$ & $\begin{array}{l}6 \cdot 4 \\
4 \cdot 5 \\
2 \cdot 6 \\
6 \cdot 4 \\
4 \cdot 6 \\
3 \cdot 5\end{array}$ & $\begin{array}{l}6 \cdot 3 \\
4 \cdot 4 \\
1 \cdot 9 \\
6 \cdot 5 \\
4 \cdot 6 \\
3 \cdot 2\end{array}$ & $\begin{array}{l}6 \cdot 1 \\
4 \cdot 0 \\
2 \cdot 0 \\
6 \cdot 3 \\
4 \cdot 3 \\
2 \cdot 9\end{array}$ & $\begin{array}{l}6 \cdot 4 \\
4 \cdot 5 \\
2 \cdot 3 \\
6 \cdot 4 \\
4 \cdot 6 \\
3 \cdot 3\end{array}$ & $\begin{array}{l}6 \cdot 3 \\
4 \cdot 5 \\
2 \cdot 2 \\
6 \cdot 5 \\
4 \cdot 6 \\
3 \cdot 1\end{array}$ & $\begin{array}{l}6 \cdot 4 \\
3 \cdot 6 \\
1 \cdot 7 \\
6 \cdot 1 \\
4 \cdot 5 \\
2 \cdot 6\end{array}$ & $\begin{array}{l}6 \cdot 3 \\
4 \cdot 2 \\
2 \cdot 1 \\
6 \cdot 4 \\
4 \cdot 8 \\
2 \cdot 8\end{array}$ & $\begin{array}{l}6 \cdot 3 \\
4.3 \\
2 \cdot 1 \\
6.4 \\
4.4 \\
2.6\end{array}$ \\
\hline Turret & $\begin{array}{l}4 \\
6 \\
8 \\
4 \\
6 \\
8\end{array}$ & $\begin{array}{l}9 \cdot 0 \\
5 \cdot 5 \\
3 \cdot 1 \\
4 \cdot 6 \\
3 \cdot 0 \\
1 \cdot 9\end{array}$ & $\begin{array}{l}8 \cdot 7 \\
5 \cdot 8 \\
3 \cdot 6 \\
4 \cdot 7 \\
3 \cdot 2 \\
1.9\end{array}$ & $\begin{array}{l}9 \cdot 1 \\
5 \cdot 7 \\
3 \cdot 6 \\
4 \cdot 7 \\
3 \cdot 2 \\
2 \cdot 0\end{array}$ & $\begin{array}{r}10.0 \\
5.7 \\
3.5 \\
4.8 \\
2.9 \\
1.9\end{array}$ & $\begin{array}{r}10 \cdot 1 \\
6 \cdot 8 \\
4 \cdot 1 \\
4 \cdot 8 \\
3 \cdot 2 \\
1 \cdot 7\end{array}$ & $\begin{array}{r}10.6 \\
7.0 \\
4 \cdot 1 \\
4 \cdot 8 \\
2.9 \\
1.7\end{array}$ & $\begin{array}{l}9.9 \\
5 \cdot 5 \\
3.4 \\
4 \cdot 5 \\
2.8 \\
1.4\end{array}$ & $\begin{array}{r}10.6 \\
6.7 \\
3.9 \\
4.6 \\
3.0 \\
1.6\end{array}$ & $\begin{array}{r}10.5 \\
6.5 \\
4.1 \\
4.6 \\
3.0 \\
1.8\end{array}$ \\
\hline
\end{tabular}

$\dot{\mathrm{V}}$-flow of compressed air; $\mathrm{T}=0^{\prime}, 3^{\prime}, 6^{\prime}$-aerosol measured immediately after the start of nebulisation and at three and six minutes. 


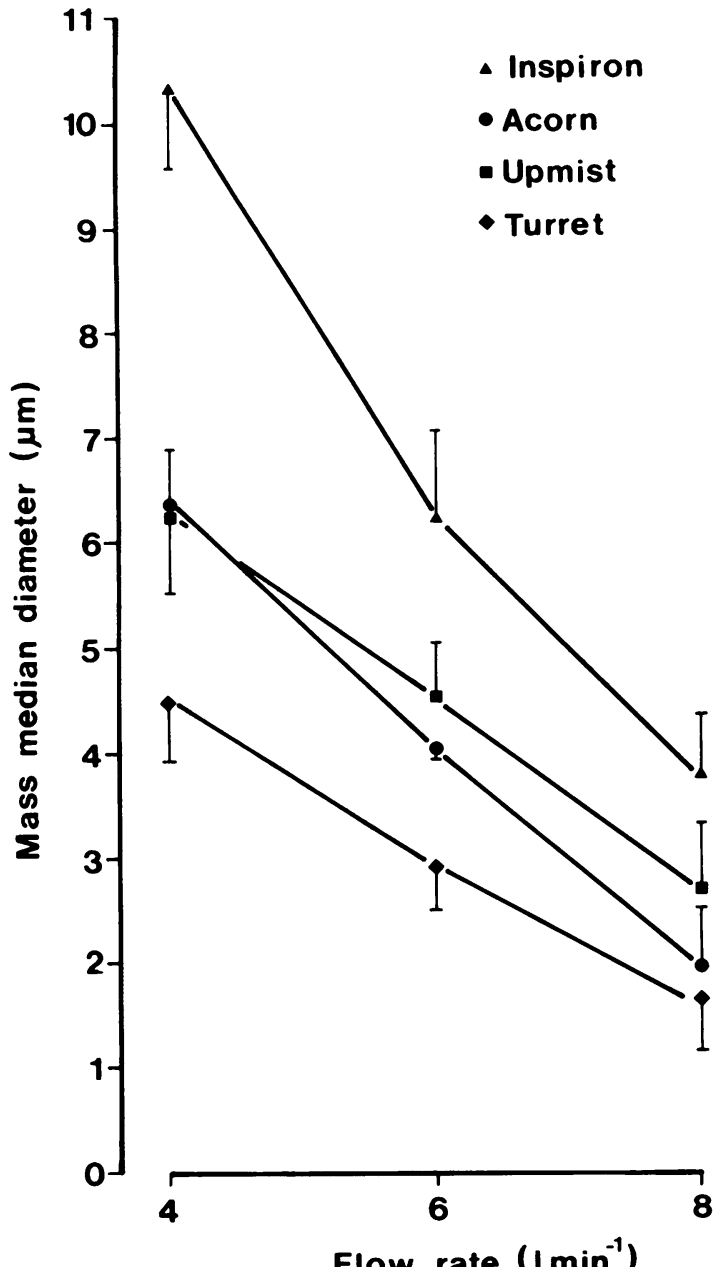

Fig 1 Effect of varying the flow rate of compressed air used to drive the nebulisers on the mass median diameter of aerosol generated. The points shown represent the pooled data for concentration and nebulisation time and are the means and standard errors for the five nebulisers of each make assessed.

aerosol mass median diameter in every case. The data for the different nebulisation times and respirator solutions were therefore pooled to assess this effect (fig 1). By increasing the flow rate from 4 to $61 \mathrm{~min}^{-1}$ and from 6 to $81 \mathrm{~min}^{-1}$ there was a significant reduction $(p<0.01)$ in mass median diameter of all the aerosols sampled on both occasions. An overall $50 \%$ reduction in mass median diameter could be achieved by increasing the flow rate from 4 to $81 \mathrm{~min}^{-1}$.

At $81 \mathrm{~min}^{-1}$ there was no significant difference between the mass median diameters of aerosols from the Acorn and Turret nebulisers or between

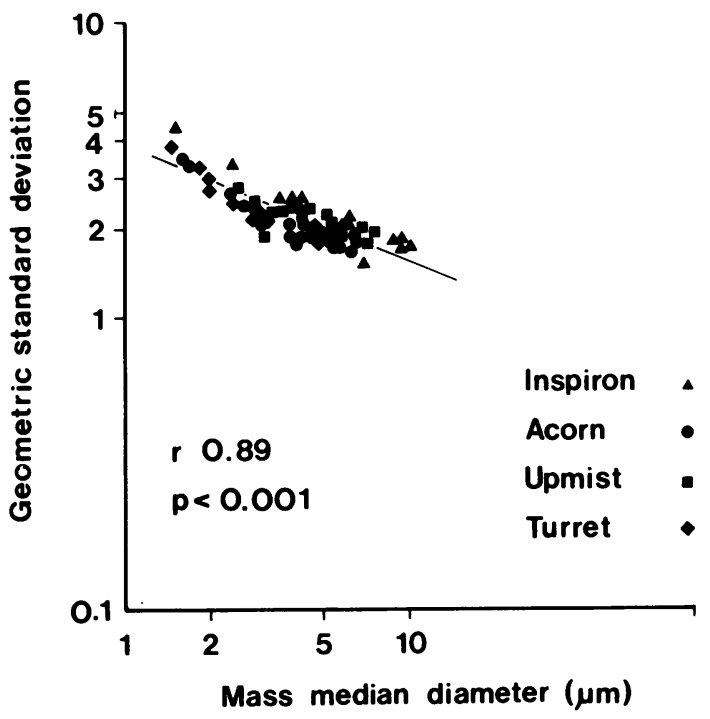

Fig 2 Relationship between the mass median diameter and geometric standard deviation of the aerosols generated. Each point represents the mean of the three measurements taken during nebulisation for each individual nebuliser.

the aerosols from the Upmist and Inspiron Mini-neb nebulisers. At $61 \mathrm{~min}^{-1}$ the Turret nebulisers generated aerosols significantly smaller $(p<0.05)$ than the Acorn, Upmist, and Inspiron Mini-neb nebulisers, and the Inspiron Mini-neb generated aerosols significantly larger than Turret, Acorn, and Upmist nebulisers $(p<0.05)$. Similar differences were observed at the lower flow rate of $41 \mathrm{~min}^{-1}$, at which the Inspiron Mini-neb generated aerosols with mass median diameters more than double those from the Turret nebulisers.

The aerosols studied in these experiments were all found to be heterodisperse with regard to their size distributions. Figure 2 shows the relationship observed between the mass median diameter and geometric standard deviation of the aerosols sampled. An inverse relation was found between the two parameters, a small mass median diameter being obtained at the expense of a large geometric standard deviation or more heterodisperse size distribution. Application of linear regression analysis (by the method of least squares) showed that In geometric standard deviation $=1.37-0.4 \mathrm{ln}$ mass median diameter $(r=0.89, p<0.001)$.

Despite the increased heterodispersity of the aerosols, the proportion of the mass of particles of less than $5 \mu \mathrm{m}$ was found to increase with increased flow rate (fig 3 ).

During the experimental period of one month the mean (SD) ambient temperature and relative 


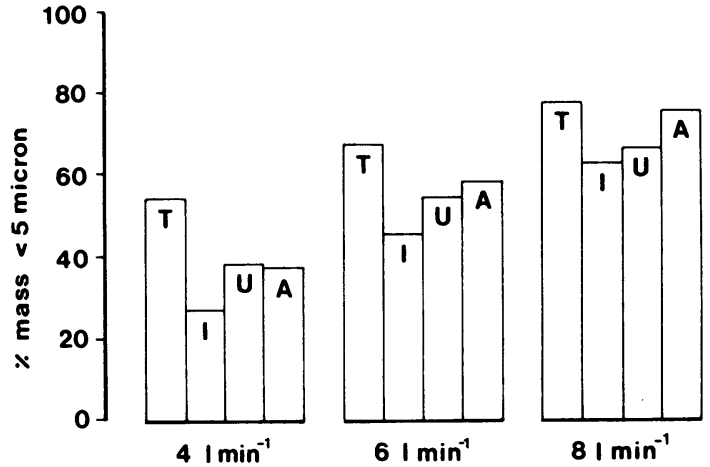

Fig 3 Percentage of the mass or volume of the respirator solutions contained in droplets smaller than 5 um for each make of nebuliser at the three air flow rates studied.

T-Turret; I-Inspiron Mini-neb; U-Upmist; A-Acorn.

humidity were found to be $18 \cdot 3^{\circ} \mathrm{C}\left(0 \cdot 9^{\circ}\right)$ and $51 \%$ $(5 \cdot 8 \%)$ respectively.

\section{Discussion}

The flow rate of compressed air used to drive the nebulisers has a major influence on aerosol size distribution. The differences in mass median diameter observed at the three flow rates would be sufficient to cause appreciable changes in the sites of aerosol deposition in the lung. To generate an aerosol with a mass median diameter of less than $5 \mu \mathrm{m}$ a minimum air flow rate of $61 \mathrm{~min}^{-1}$ should be used to drive the Acorn and Upmist nebulisers, while the Inspiron Mini-neb should be driven at the higher flow rate of $81 \mathrm{~min}^{-1}$. Only the Turret nebuliser will generate an aerosol with a mass median diameter of less than $5 \mu \mathrm{m}$ at $41 \mathrm{~min}^{-1}$. Domiciliary oxygen cylinders usually have two fixed flow rate settings, 2 and $41 \mathrm{~min}^{-1}$, and our results show that the higher flow rate would be inadequate to drive the Acorn, Upmist, and Inspiron Mini-neb nebulisers.

At higher flow rates the differences between the mass median diameter of aerosols from the makes of nebuliser were reduced, but in all cases the aerosols were more heterodisperse. The effect of increases in heterodispersity on aerosol deposition site in the lung is the subject of debate. Gonda ${ }^{10}$ has proposed that for aerosols with a large geometric standard deviation the mass median diameter becomes a less reliable indicator of where the aerosol will be deposited in the lung. The Task Group on Lung Dynamics, ${ }^{11}$ however, showed only a $10 \%$ change in the regional deposition of an aerosol with a mass median diameter of $2 \mu \mathrm{m}$ when the geometric standard deviation was changed from 1.5 to $4.0 \mu \mathrm{m}$. The clinical implications of increased heterodispersity await investigation; but an aerosol with a small mass median diameter and large geometric standard $\stackrel{\rho}{\rightarrow}$ deviation might be predicted to show more ubiqui- $\bar{C}$ tous deposition throughout the lung, thereby deliv- 흘 ering a bronchodilator aerosol to a wider surface $\frac{\bar{\omega}}{\partial}$ area.

Detailed examination of the aerosol size distributions showed that at high air flow rates the aerosols showed polymodality, which could be attributed to droplet disintegration and coagulation within the $\vec{\omega}$ nebulisers. Under these circumstances the aerosols $\stackrel{\circ}{\circ}$ no longer conform to a log normal size distribution $\vec{x}$ and the geometric standard deviation may be a less $\dot{\omega}$ reliable description of the aerosol size distribution. $\stackrel{\oplus}{-}$ It may therefore be more useful to specify the prop- $\overrightarrow{0}$ ortion of the aerosol mass which lies within the of optimum size range for therapeutic aerosols (less than $5 \mu \mathrm{m}$ in diameter).

Our results indicate that the size distribution of $\overrightarrow{0}$ aerosols from the makes of nebuliser studied do not vary during nebulisation to an extent which would $\overrightarrow{0}$ cause changes in the site of deposition in the lung. ㄱ. The temperature of the respirator solution falls $\vec{\varphi}$ rapidly during nebulisation to about $10^{\circ} \mathrm{C}$ below the $\underset{\omega}{\infty}$ ambient temperature, causing changes in the surface tension and viscosity of the solution and reducing the rate of aerosol release from the nebulisers. ${ }^{12}$ The effect on aerosol size distribution, however, is small. The concentration of terbutaline in the respirator $\frac{0}{D}$ solution similarly had little effect on the aerosol size $\varrho$ distribution, although other types of respirator solution with different physical properties, such as highly viscid antibiotics, may exert greater effects. ${ }^{13}$

These measurements were all made undet ambient conditions of temperature and relative humidity reflecting the size distribution of the aerosols at the mouthpiece of the nebulisers. From this point the aerosols will be drawn into the lung, $\underline{3}$. where the physiological conditions of temperature and relative humidity $\left(37^{\circ} \mathrm{C}\right.$ and $>99.5 \%$ respectively) will result in changes in the size distribution of the aerosol. Swelling or shrinkage of the droplets may occur as the aerosol adjusts to attain equilib- $\frac{D}{0}$ rium with its environment. The changes in size distibution of the aerosols have not been taken into $N$ account in this study but they will depend on the chemical structure of the droplets and the concent- $N$ ration of salts within them. ${ }^{14}$ The site of aerosol $\omega$ deposition within the lung may be affected if there is?

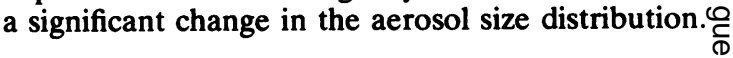

We wish to thank Dr AG Jones of the department ${ }^{+}$ of chemical and biochemical engineering at University College London for allowing us to use their $\stackrel{0}{\mathbb{D}}$

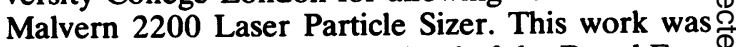
funded by the Peter Samuel Fund of the Royal Free $\stackrel{\mathbb{Q}}{2}$ 
Hospital and Astra Pharmaceuticals Ltd.

\section{References}

${ }^{1}$ Woolcock AJ. Inhaled drugs in the prevention of asthma. Am Rev Respir Dis 1977;115:191-4.

${ }^{2}$ Miller WF. Aerosol therapy in acute and chronic respiratory disease. Arch Intern Med 1973;131:14855.

${ }^{3}$ Hodson M, Penketh A, Batten JC. Aerosol carbenicillin and gentamicin treatment of Pseudomonas aeruginosa infection in patients with cystic fibrosis. Lancet 1981 ;ii:1137-9.

${ }^{4}$ Paterson JW, Woolcock AJ, Shenfield GM. Bronchodilator drugs. Am Rev Respir Dis 1979;120: 1149-88.

${ }^{5}$ Heyder J, Gebhart J, Stahlhofen W. Inhalation of aerosols: particle deposition and retention. In: Willeke K, ed. Generation of aerosols. Ann Arbor: Ann Arbor Science Publishers, 1980.

${ }^{6}$ Rees BJ, Clark TJH. The importance of particle size in response to inhaled bronchodilators. Eur J Respir Dis 1982;63,suppl 119:73-8.
${ }^{7}$ Mercer TT, Tillery MI, Chow HY. Operating characteristics of some compressed air nebulisers. Am Ind Hyg Assoc J 1968;29:66-78.

${ }^{8}$ Lourenco RV, Cotromanes E. Clinical aerosols. 1Characterisation of aerosols and their diagnostic uses. Arch Intern Med 1982;142:2163-72.

${ }^{9}$ Siegel S. Non parametric statistics for behavioural sciences. Tokyo: McGraw-Hill, Kogakusha, 1956.

${ }^{10}$ Gonda I. Study of the effects of polydispersity of aerosols on regional deposition in the respiratory tract. J Pharm Pharmacol 1981;33,suppl:52P.

1 Task Group on Lung Dynamics. Deposition and retention models for internal dosimetry of the human respiratory tract. Health Phys 1966;12:173-208.

${ }^{12}$ Clay M, Pavia D, Newman SP, Clarke SW. Efficiency of jet nebulisers in the production of therapeutic aerosols. Thorax 1982;37:788(abstract).

${ }^{13}$ Swift DL. Aerosols and humidity therapy. Am Rev Respir Dis 1980;122:71-7.

${ }_{14}$ Davis SS, Burb MD. Physico-chemical studies on aerosol solutions for drug delivery. 3-The effect of relative humidity on the particle size of inhalation aerosols. Int J Pharmaceutics 1978;1:303-14. 